\title{
Development of an Ibuprofen-Releasing Biodegradable PLA/PGA Electrospun Scaffold for Tissue Regeneration
}

\author{
Irene Cantón, ${ }^{1}$ Robert Mckean, ${ }^{2}$ Mirren Charnley, ${ }^{1}$ Keith A. Blackwood, ${ }^{1}$ \\ Calogero Fiorica, ${ }^{3}$ Anthony J. Ryan, ${ }^{2}$ Sheila MacNeil ${ }^{1}$ \\ ${ }^{l}$ Department of Engineering Materials, University of Sheffield, Kroto Research Institute, \\ Broad Lane, Sheffield S3 7HQ, UK; telephone: 44-114-222-5993; fax: 44-114-222-5945; \\ e-mail: s.macneil@sheffield.ac.uk \\ ${ }^{2}$ Department of Chemistry, University of Sheffield, Sheffield, UK \\ ${ }^{3}$ Dipartimento di “Chimica e Tecnologie Farmaceutiche" Università degli studi di Palermo, \\ Palermo, Italy
}

Received 12 May 2009; revision received 28 August 2009; accepted 31 August 2009

Published online 3 September 2009 in Wiley InterScience (www.interscience.wiley.com). DOI 10.1002/bit.22530

\begin{abstract}
Our aim was to develop a biodegradable fibrous dressing to act as a tissue guide for in situ wound repair while releasing Ibuprofen to reduce inflammation in wounds and reduce pain for patients on dressing changes. Dissolving the acid form of Ibuprofen (from $1 \%$ to $10 \%$ by weight) in the same solvent as $75 \%$ polylactide, $25 \%$ polyglycolide (PLGA) polymers gave uniformly loaded electrospun fibers which gave rapid release of drug within the first $8 \mathrm{~h}$ and then slower release over several days. Scaffolds with $10 \%$ Ibuprofen degraded within 6 days. The Ibuprofen released from these scaffolds significantly reduced the response of fibroblasts to major pro-inflammatory stimulators. Fibroblast attachment and proliferation on scaffolds was unaffected by the addition of 1-5\% Ibuprofen. Scaffolds loaded with $10 \%$ Ibuprofen initially showed reduced cell attachment but this was restored by soaking scaffolds in media for $24 \mathrm{~h}$. In summary, addition of Ibuprofen to electrospun biodegradable scaffolds can give acute protection of adjacent cells to inflammation while the scaffolds provide an open 3D fibrous network to which cells can attach and migrate. By 6 days, such scaffolds will have completely dissolved into the wound bed obviating any need for dressing removal.

Biotechnol. Bioeng. 2010;105: 396-408.

(C) 2009 Wiley Periodicals, Inc.
\end{abstract}

KEYWORDS: biodegradation; drug release; inflammation; wound healing

Correspondence to: S. Macneil

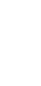


new tissue formation but also to release the antiinflammatory Ibuprofen to reduce pain for the patients and reduce the excessive inflammation of the wound bed which can prevent healing.

Dressings designed to reduce pain and accelerate healing are not new-occlusive dressings to achieve these ends were first introduced in 1948 (Gilje, 1948). These allow more rapid re-epithelialization by reducing scab formation, and also decrease the chances of gauze or fibrous dressings sticking to the wounds and causing re-injury upon dressing removal (Hinman and Maibach, 1963). However, these dressings still need to be removed. Pain relief in wound healing is positive for the patient in many ways as pain promotes psychological stress in patients (Christian et al., 2006) while pain relief allows patients to bear compression therapy, which is often beneficial in chronic wound healing (Price et al., 2007, 2008). Unfortunately, systemic pain relief has not proven very efficient in tackling chronic wound pain as the pain relief from most medications lasts only minutes or hours (Cardenas and Jensen, 2006) and there are concerns about patients becoming addicted to painkillers.

Encouragingly recent studies have shown beneficial effects on wound pain with the use of dressings that slowly release Ibuprofen without compromising wound healing (Gottrup et al., 2002; Jorgensen et al., 2006). A biodegradable dressing that does not need to be removed would be highly desirable for the treatment of this type of wound.

Additionally there are many thousands of patients a year (usually young children) who suffer superficial scald injuries. While these will usually heal well, if not infected, pain management is an issue especially at dressing changes which can be very traumatic for young children. A dressing which releases a painkiller and degrades into the wound bed and is open to exudate (which can be extensive in partial thickness burns) would be valuable if the fibers of this dressing also acted as tissue guides for the reepithelialization of these wounds.

We recently developed synthetic biodegradable electrospun scaffolds as substrates for tissue engineering of skin and oral mucosa. These are based on PLGA random multiblock copolymers as described in detail in Blackwood et al. (2008). These materials are FDA approved. Extensive research into the degradation of PLLA and PGA show these to be hydrolyzed into lactic and glycolic acids, respectively. Also the breakdown rate for these scaffolds both in vitro and in vivo can be modulated by varying the ratio of glycolide to lactide (Blackwood et al., 2008; Kim et al., 2003). We also confirmed that these scaffolds supported cellular ingrowth both when implanted cell free into the flanks of rats (to study their rate of degradation) and when cultured human skin cells were placed on them in vitro. Skin cells attached and migrated along the scaffold fibers producing new collagen over the space of a few days (Blackwood et al., 2008).

In this study we aimed to develop biodegradable scaffolds for skin cell attachment and migration which also incorporate Ibuprofen to reduce pain and wound bed inflammation. The concept is that these dressings will initially release Ibuprofen but also act simultaneously as a temporary tissue guide for skin regeneration over several days, eventually degrading into the wound bed leaving skin cells in place so there will be no need to remove these dressings.

We report on the production of these Ibuprofen loaded scaffolds and the effect of the released Ibuprofen on inflammation induced in skin cells by TNF- $\alpha$ (chosen as an example of a pro-inflammatory cytokine) and by a bacterial lipopolysaccharide (LPS) chosen to represent one aspect of bacterial contamination. We also show the rate of degradation of these scaffolds in vitro and their ability to support skin cell attachment and proliferation.

\section{Materials and Methods}

\section{Scaffold Synthesis and Characterization}

\section{Polymers}

For this study three PLGA copolymers with different ratios of lactide to glycolide 75:25 $\left(M_{\mathrm{w}} 66-107 \mathrm{k}\right), 50: 50\left(M_{\mathrm{w}} 40-\right.$ $75 \mathrm{k})$, and a 1:1 blend of these two were used. All the PLGA copolymers were purchased from Sigma-Aldrich. The polymers were dissolved in dichloromethane (DCM) to form solutions of suitable viscosities for electrospinning; 75:25 and 50:50 to form 20\% and 25\% (wt/wt) solutions, respectively, and equal volumes of these solutions were used to form the blend. Ibuprofen powder (Sigma-Aldrich) was added to the polymer solutions in DCM to form homogeneous mixtures (from $1 \%$ to $10 \mathrm{wt} \%$ of Ibuprofen added relative to the weight of the polymer).

\section{Electrospinning Conditions}

Polymer solutions were loaded into $2 \mathrm{~mL}$ syringes fitted with blunt tipped stainless steel needles with an internal diameter of $0.8 \mathrm{~mm}$ (J\&J, Fairlawn, NJ, USA). The solutions were delivered at a constant feed rate of $3.5 \mathrm{~mL} / \mathrm{h}$ using a programmable syringe pump (Aladdin 1000) and were electrospun horizontally with an accelerating voltage of $15 \mathrm{kV}$ supplied by a high voltage power supply (Brandenburg, Alpha series III). Fibrous mats were collected on aluminum foil sheets $(18 \mathrm{~cm} \times 16 \mathrm{~cm})$ wrapped around an earthed aluminum rotating collector (rotating at $300 \mathrm{rpm}$ ) $20 \mathrm{~cm}$ from the tip of the needle. Jet formation/stability was assisted by means of an aluminum focusing ring at a voltage of $15 \mathrm{kV}, 5 \mathrm{~mm}$ behind the tip of the needle. Scaffolds were produced in an air-conditioned room at $21^{\circ} \mathrm{C}$ with a relative humidity of $\sim 30 \%$, followed by drying under vacuum at room temperature for a minimum of $24 \mathrm{~h}$. To analyze the environmental effect (humidity and temperature) on scaffold reproducibility, scaffolds were occasionally spun in high humidity conditions ( $>85 \%$ relative humidity) and not dried under vacuum. 


\section{Detection of Ibuprofen Release From Scaffolds by UV/Vis Spectroscopy}

The release of the Ibuprofen from the three scaffold types (each loaded with 10\% Ibuprofen) was monitored using $\mathrm{UV} / \mathrm{Vis}$ spectroscopy. A $25 \mathrm{mg}$ piece of scaffold was cut from each scaffold produced and submerged in $12 \mathrm{~mL}$ of pure water, and left at room temperature. The intensity at $222 \mathrm{~nm}$ was measured (the $\lambda_{\max }$ of IBU) at various time points up to 1 week and the values were compared with a previously calculated Ibuprofen standard curve. Three separate replicates of electrospun polymer loaded with Ibuprofen were used to determine the average Ibuprofen release profile.

\section{In Vitro Degradation of Scaffolds}

Scaffolds with or without Ibuprofen were cut into $18 \mathrm{~mm}$ disks using a tissue punch and were sterilized by gently spraying them with $70 \% \mathrm{EtOH}$ and left to dry in a sterile flow cabinet. Scaffolds were then immersed in $1 \mathrm{~mL}$ of Ringers solution with $100 \mathrm{IU} / \mathrm{mL}$ penicillin and $100 \mu \mathrm{g} / \mathrm{mL}$ streptomycin and incubated at $37^{\circ} \mathrm{C}$. To test the effect of the $\mathrm{pH}$ on the degradation of the scaffold, they were placed in Ringers solution at three different $\mathrm{pHs}(6,7.4$, and 8.5). Samples of this solution were taken daily to monitor $\mathrm{pH}$ changes. Physical changes in the scaffold mats were also recorded daily by taking optical micrographs of the scaffolds.

\section{Cell Response to Scaffolds in 2D and 3D Cultures}

\section{Culture of Normal Human Keratinocytes and Fibroblasts}

Normal human fibroblasts were isolated and cultured as described previously (Ralston et al., 1997). Passage 3-7 fibroblasts were used. Keratinocytes were cultured in Dulbecco's modified Eagle's medium (DMEM) supplemented with $10 \%(\mathrm{v} / \mathrm{v})$ fetal calf serum (FCS), $2 \mathrm{mM}$ glutamine, $0.625 \mu \mathrm{g} / \mathrm{mL}$ amphotericin $\mathrm{B}, 100 \mathrm{IU} / \mathrm{mL}$ penicillin, and $100 \mu \mathrm{g} / \mathrm{mL}$ streptomycin. Preparation of 3D tissue engineered constructs either in Azowipe ${ }^{\circledR}$ scaffolds (non-woven viscose rayon microfiber scaffolds bonded with styrene butadiene copolymer, Vernon-Carus, Chorley, UK) or PLGA 75:25 scaffolds was performed as previously described (Blackwood et al., 2008).

\section{Detection of Cellular Metabolic Activity Via MTT-ESTA Assay}

The effect of Ibuprofen (sodium salt or isomer mixture; Sigma-Aldrich, Poole, UK) on cell metabolic activity was studied by adding Ibuprofen directly onto the cells or by examining its release from scaffolds both in monolayers (2D) and in 3D scaffolds. For 2D analysis, $3 \times 10^{4} \mathrm{HDF}$ cells/ well were cultured in 24 well plates until $80 \%$ confluent. For $3 \mathrm{D}$ analysis, $3 \times 10^{5} \mathrm{HDF}$ cells/well were cultured in 12 well plates in two layers of a viscose rayon scaffold for $48 \mathrm{~h}$. Scaffolds (with and without Ibuprofen) were placed above cultured cells using co-culture inserts so that scaffolds were immersed in the same media as the cells for $24 \mathrm{~h}$ but were physically separated from the fibroblasts. Cellular metabolic activity (in 2D or 3D) was assessed using MTT (3-(4,5dimethylthiazol-2-yl)-2,5 diphenyl tetrazolium bromide) (Sigma-Aldrich, St Louis, MO). Briefly, cells were washed three times in PBS, and then incubated with MTT solution $(0.5 \mathrm{mg} / \mathrm{mL}$ MTT in PBS, 1 and $2 \mathrm{~mL}$ per well of 24 and 12 well plates, respectively) for $1 \mathrm{~h}$ at $37^{\circ} \mathrm{C}$ in a humidified incubator $\left(5 \% \mathrm{CO}_{2} / 95 \%\right.$ air). In healthy viable cells, MTT is reduced to a purple colored formazan salt by the activity of the mitochondrial enzyme succinyl dehydrogenase. After $60 \mathrm{~min}$, the solution was aspirated and the insoluble intracellular formazan product was solubilized and released from cells by adding iso-propanol $(0.5 \mathrm{~mL}$ per well of 24 well plate or $1 \mathrm{~mL} / \mathrm{cm}^{2}$ cultured tissue) and incubated for $10 \mathrm{~min}$. The optical density at $490 \mathrm{~nm}$ with a reference wavelength of 620 was then measured using a plate reading spectrophotometer.

\section{Visualization of Cells Grown Within Scaffolds by Staining for Collagen Production}

To analyze the effect of environmental spinning conditions (humidity and temperature) on the physical structure of the scaffolds and on cell growth, 3D cultures on PLGA scaffolds electrospun under different conditions were tested for collagen deposition. Collagen deposition on scaffold fibers was analyzed as described in Blackwood et al. (2008). Briefly, constructs were grown for 7 days then washed three times in PBS and fixed in 4\% formalin. Following three washes with PBS the constructs were stained for collagen deposition in a $0.1 \%$ solution of Sirius Red F3B (C.I. 35780, Direct Red 80, Sigma-Aldrich) in saturated picric acid for $18 \mathrm{~h}$. Afterward, the constructs were washed with water until no more red coloring was eluted. Scaffolds stained with picrosirius red were then photographed with a digital camera.

\section{Investigation of the Anti-Inflammatory Effect of Ibuprofen and Ibuprofen Loaded Scaffolds by Immunolabeling of Fibroblasts for the Detection of NF- $\kappa B / p 65$ Activation}

LPS from E. coli serotype O111:B4 (Sigma-Aldrich) at $100 \mathrm{ng} / \mathrm{mL}$ or TNF- $\alpha$ (Sigma-Aldrich) at $1,000 \mathrm{U} / \mathrm{mL}$ was used as a positive control for activation of NF-кB in fibroblasts. In preliminary experiments, Ibuprofen $\left(10^{-3}\right.$ and $10^{-4} \mathrm{M}$, sodium salt and isomer mixture; SigmaAldrich, UK) was used to down regulate NF- $\mathrm{KB}$ activation. Then the 10\% Ibuprofen loaded PLGA scaffolds (75/25, 50/ 50, and a 1:1 blend of these two) were examined. Negative controls were produced by incubating cells in normal DMEM. All experiments were performed in triplicate. 
Following the Ibuprofen treatments, monolayers were washed in PBS and the cells were fixed in 10\% formalin (500 $\mathrm{L} /$ well) for $30 \mathrm{~min}$. Cell monolayers were washed a further three times in PBS, prior to cell permeabilization with $0.1 \%$ Triton X100 for $20 \mathrm{~min}$. Subsequently, cells were washed three times with PBS. Unreactive binding sites were blocked by adding a 5\% dried milk powder solution to each well for $1 \mathrm{~h}$. A further three washes in PBS were performed prior to incubation with the first antibody solution. The first antibody (rabbit polyclonal antihuman IgG NF-кB p65 C-20, Santa Cruz Biotechnology Inc., Santa Cruz, CA) was added at a concentration of 1:100 in 1\% PBS-dried milk powder. Cells were incubated in the antibody solution at $4{ }^{\circ} \mathrm{C}$ for $18 \mathrm{~h}$. The cells were washed three more times in PBS. Afterward, cells were incubated with biotinylated goat antirabbit $(1: 1,000)$ (Vector Laboratories, Burlingame, CA) in $1 \%$ PBS-milk powder. The cells were then washed a further three times in PBS. Streptavidin-FITC (Vector Laboratories) conjugate was then added to the wells at a concentration of 1:100 in PBS. A further three washes in PBS were performed. After this time, the fluorescent staining were visualized using an AXON image express system (Axon Instruments/Molecular Devices, Union City, CA). Briefly, fluorescence micrographs of immunolabeled samples were taken using epifluorescent illumination at $\lambda_{\mathrm{ex}} 495 \mathrm{~nm}, \lambda_{\mathrm{em}}$ $515 \mathrm{~nm}$ (for FITC visualization); $\lambda_{\mathrm{ex}} 358 \mathrm{~nm}, \lambda_{\mathrm{em}} 461 \mathrm{~nm}$ (for DAPI visualization). DAPI fluorescence was used to identify nuclear position. The boundary between nucleus and cytoplasm was delimited by analysis software (ImageXpress Console 1.0) using DAPI micrographs in a sample of at least 100 cellular counts per visual field. Within the defined region, the intensity of FITC $(\mathrm{NF}-\kappa \mathrm{B} / \mathrm{p} 65)$ labeling was used to calculate activation for each micrograph and sample. The calculation of NF- $\kappa \mathrm{B}$ activation was performed manually according to intracellular position, as previously described in Moustafa et al., 2002 and Cantón et al., 2007, where total nuclei localization indicates full activation of NF- $\kappa \mathrm{B}$ and the absence of nuclear localization indicates inactive NF-кB. p65 labeling in both nuclei and cytosol was taken as partial activation. The analysis of the micrographs was done in triplicate.

For cells cultured in 3D scaffolds the methodologies used were described in Sun et al. (2004). For investigation of fibroblast attachment and migration on Ibuprofen loaded scaffolds, this was examined by loading cells onto scaffolds containing $0 \%, 2 \%, 5 \%$, and $10 \%$ Ibuprofen and culturing cells for 7 days prior to assessment of cell viability using MTT ESTA. In these experiments some samples of scaffolds were washed by soaking in media for various periods of $1-48 \mathrm{~h}$ prior to cell addition as indicated.

\section{Statistics}

Student's unpaired $t$-test was used to assess the significance of differences between results.

\section{Results}

\section{Scaffold Synthesis and Characterization}

\section{Development of Reproducible Spinning Conditions for the Production of Electrospun Material With Ibuprofen}

PLGA scaffolds were electrospun from DCM solutions loaded with $1-10 \mathrm{wt} \%$ of Ibuprofen relative to the polymer to produce fibers in which the Ibuprofen was uniformly dispersed (see Fig. 1A, D, and F). The presence of the acid form of Ibuprofen did not significantly alter the appearance of the fibrous scaffolds as shown in Figure 1. The acid form was used as the sodium salt of Ibuprofen was insoluble in solvents suitable for processing the polymer. The latter was found to result in a heterogeneous dispersion of the drug in the spinning solution, and on spinning the drug had a tendency to come to the surface of the fibers due to the electrostatic forces involved in the process (see Fig. 1B).

Fibers produced in this way have been shown to have a rapid burst release when submerged in aqueous media (Taepaiboon et al., 2006). Accordingly to achieve a more sustained release, homogeneous solutions of the polymer and Ibuprofen isomer mixture (acid form) were prepared in DCM for all subsequent studies.

The concentrations of the various polymers and the electrospinning parameters were as previously described by us (Blackwood et al., 2008). Ibuprofen (1-10 wt $\%$, relative to the polymer) was added and each solution was thoroughly dissolved prior to spinning. For the 1:1 "blend" of polymers, equal volumes of the solutions of PLGA 50/50 (with Ibuprofen) and 75/25 (with Ibuprofen) were mixed.

The temperature and humidity of the environment in which the electrospinning was performed strongly influenced the physical properties of the scaffold. Due to the rapid solvent evaporation of the spinning solution as the ejected fiber dries, it becomes cooler than its surroundings and water vapor condenses upon it. Spinning in humid conditions produced scaffolds which cells contracted independent of the cell type grown on them or the presence or absence of serum in the medium (Fig. 2A). Here it can be seen that after only a few days in culture with cells (fibroblast, keratinocytes, and co-cultures of both), the scaffolds underwent obvious physical modifications (contraction, loss of thickness, and the fibers merged together to give a porous film-like morphology). However, vacuum drying the scaffolds immediately after spinning, in order to thoroughly remove any surface water, produced scaffolds that were much more resistant to cell contraction as seen in Figure 2B.

\section{Ibuprofen Release From the Scaffolds and In Vitro Degradation of Scaffolds}

The release of the Ibuprofen from the three scaffold types (each containing 10\% Ibuprofen) was monitored using UV/Vis spectrometry. For each experiment, a piece of 

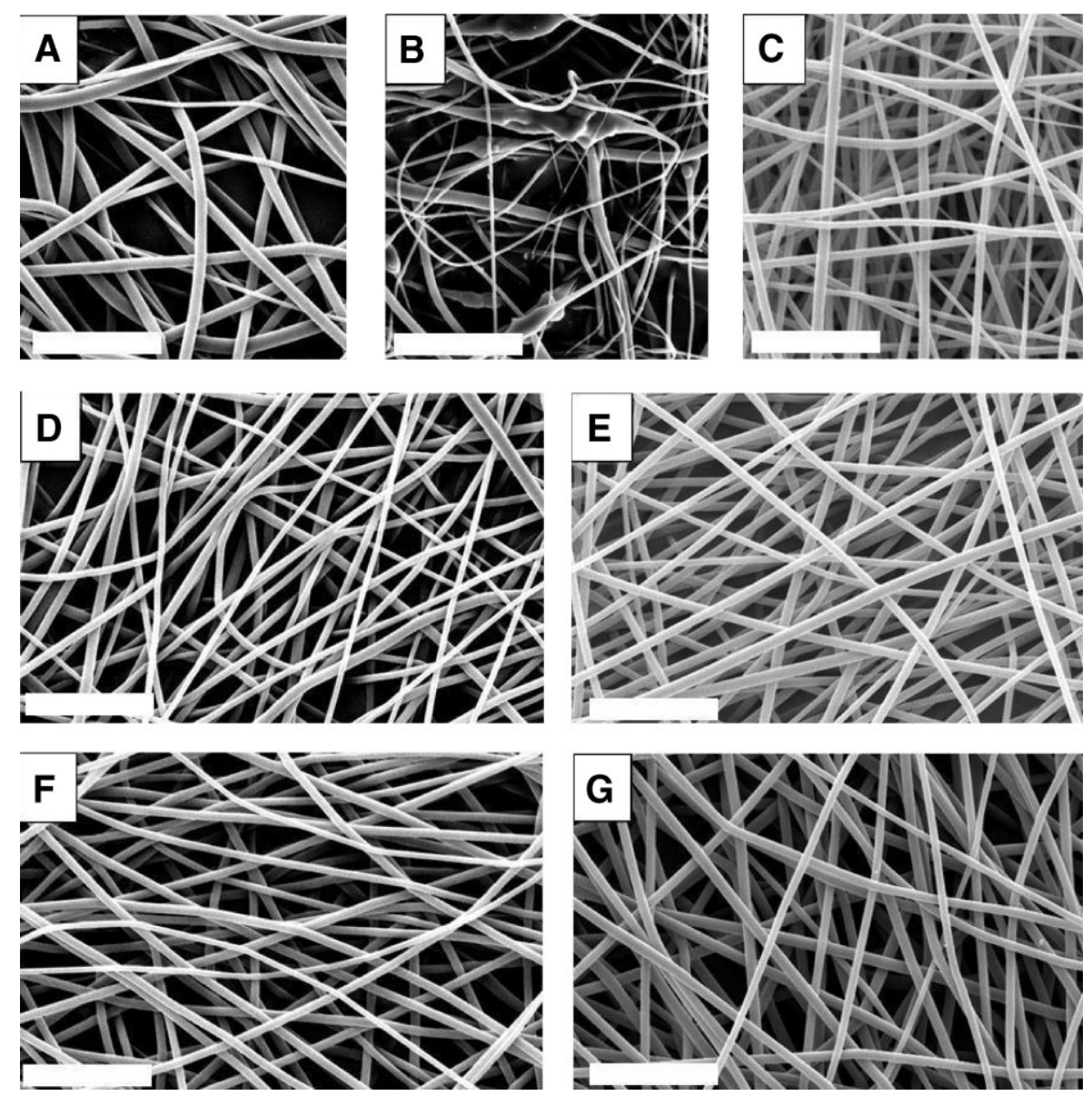

Figure 1. SEM images of electrospun PLGA fibers. A: 50/50 PLGA with 10 wt\% Ibuprofen. B: $50 / 50$ PLGA with 10 wt\% Ibuprofen sodium salt. C: $50 / 50$ PLGA without Ibuprofen. D: 1:1 blend of 50/50 and 75/25 PLGA with 10 wt\% Ibuprofen. E: 1:1 blend of 50/50 and 75/25 PLGA without Ibuprofen. F: 75/25 PLGA with 10 wt\% Ibuprofen. G: 75/25 PLGA without Ibuprofen. Scale bar $=50 \mu \mathrm{m}$.

scaffold of $25 \mathrm{mg}$ was cut and submerged in $12 \mathrm{~mL}$ of pure water. This corresponded to around $2.5 \mathrm{mg}$ of Ibuprofen per sample. The release of Ibuprofen from the samples was monitored with UV/Vis spectroscopy at $222 \mathrm{~nm}$ (the $\lambda_{\max }$ of Ibuprofen) at various time points and compared to a calibrated standard curve. The release profiles for the three scaffolds are shown in Figure 3A and B. Results shown are means of three separate replicates of electrospun scaffold.

All the scaffolds showed similar overall behavior, with an initial rapid release of drug during the first $5 \mathrm{~h}$ (as shown in Fig. 3A and on an expanded scale in Fig. 3B). Both the PLGA $50: 50$ and the blend released approximately $15 \%$ of their total Ibuprofen, and the 75:25 released approximately $4.5 \%$ of its total Ibuprofen in the first $5 \mathrm{~h}$. This initial rapid release of Ibuprofen was then followed by a steady sustained release over the following 7 days (as shown in Fig. 3A), by which point none of the scaffolds had totally released the drug. By the end of 7 days the amounts released into the $12 \mathrm{~mL}$ of water over this period were $3.5 \mu \mathrm{mol}$ for both the PLGA 50:50 and the blend of 75:25 and $1.6 \mu \mathrm{mol}$ for the PLGA $75: 25$. This corresponds to approximately $30 \%$ release for the PLGA 50:50 and the blend of 75:25 and 50:50 and approximately $15 \%$ for the PLGA $75: 25$.

Previous work within this group has demonstrated that the higher the percentage of glycolide to lactide in the copolymer, the faster the breakdown of the scaffolds both in vivo and in vitro (Blackwood et al., 2008). The 50/50 scaffold broke down very rapidly (within a week in vitro) compared to those composed of $75 \%$ lactide and $25 \%$ glycolide which took around 3 months. Thus initially we focused on the 50/50 scaffold as the best candidate for an Ibuprofen releasing dressing which would degrade into the wound bed. However, the hydrolytic degradation of PLGA is acid catalyzed and we hypothesized that the presence of Ibuprofen (acidic) within the scaffold could have an effect on the breakdown rate of the scaffold.

Accordingly we investigated the effect of including Ibuprofen in the scaffolds on the in vitro degradation of scaffolds with different ratios of lactide to glycolide (50/50, $75 / 25$, and a $1: 1$ blend of 50/50 and 75/25). Also as it has been reported that the $\mathrm{pH}$ in non-healing wounds can range from acidic to basic (Dissemond et al., 2003), we mimicked 


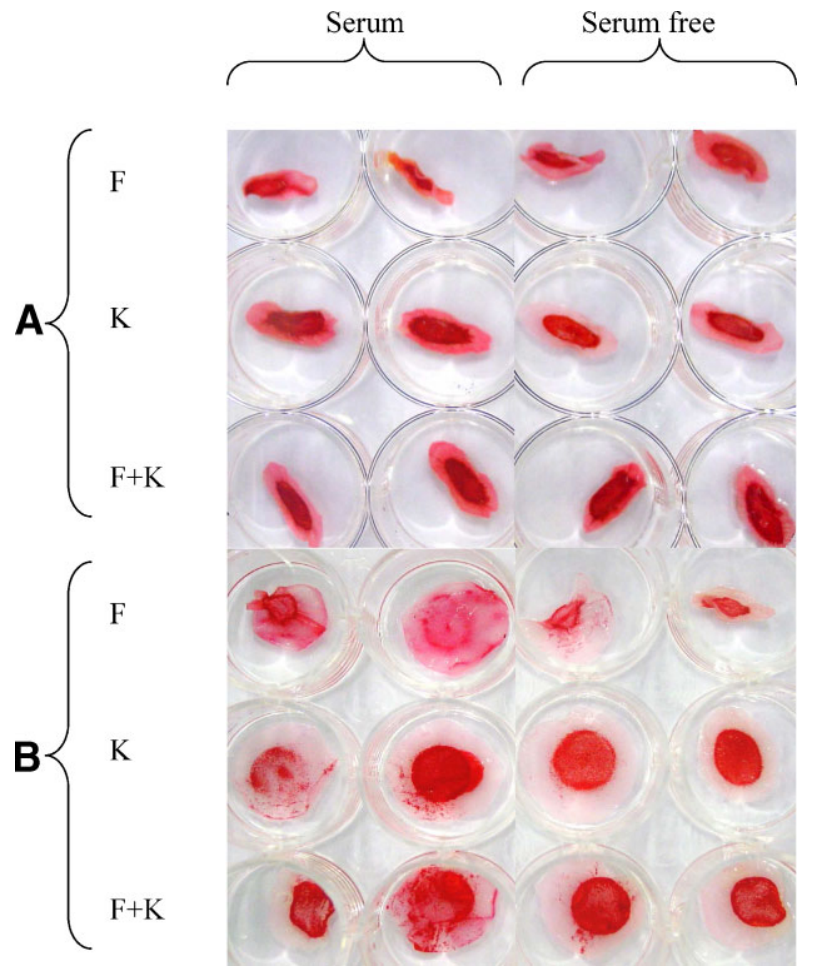

Figure 2. Effect of environmental conditions on electrospun PLGA 75:25 scaffolds. Sirius red staining of collagen deposition of human fibroblasts (F), keratinocytes $(K)$, and co-cultures of both $(F+K)$ grown for 1 week (in serum or serum-free conditions) in 75:25 PLGA scaffolds spun in different conditions. A: Scaffolds were spun in high humidity $(>85 \%)$. B: As for (A), but then immediately after spinning, scaffolds were dried under high vacuum at room temperature for $24 \mathrm{~h}$.

these variations in $\mathrm{pH}$ in vitro in Ringer's solution to $\mathrm{pH}$ 6, 7.4, and 8.5. In Figure 4 we show optical micrographs of some of the $75: 25$ scaffold fibers at times 0,1 , and 6 days with and without Ibuprofen. Table I summarizes the degradation data from these experiments.

To begin with, all the scaffolds looked similar (with fibers ranging from 2 to $5 \mu \mathrm{m}$ ) whether scaffolds contained Ibuprofen or not (Fig. 4). However, by day 6 the scaffolds carrying Ibuprofen had lost all structural integrity. In contrast the PLGA scaffolds (irrespective of the glycolide content) without Ibuprofen maintained similar appearances to those seen at day 0 (Fig. 4 and Table I).

This degradation was also independent of the initial $\mathrm{pH}$ of the Ringer's solution which did not change significantly from the $\mathrm{pH}$ of 4-5 seen in the Ringer's solution around the scaffold at day 1 . This did not change significantly over 6 days of the experiment (Table I).

As summarized in Table I the content of glycolide was a key factor in speeding up the rate of degradation of the fibers. The PLGA 50/50 scaffold had the fastest rate of degradation with Ibuprofen present, indeed by day 1 the physical structure of the Ibuprofen 50/50 scaffold showed some merging of fibers (as shown in Fig. 4C and summarized in Table I).
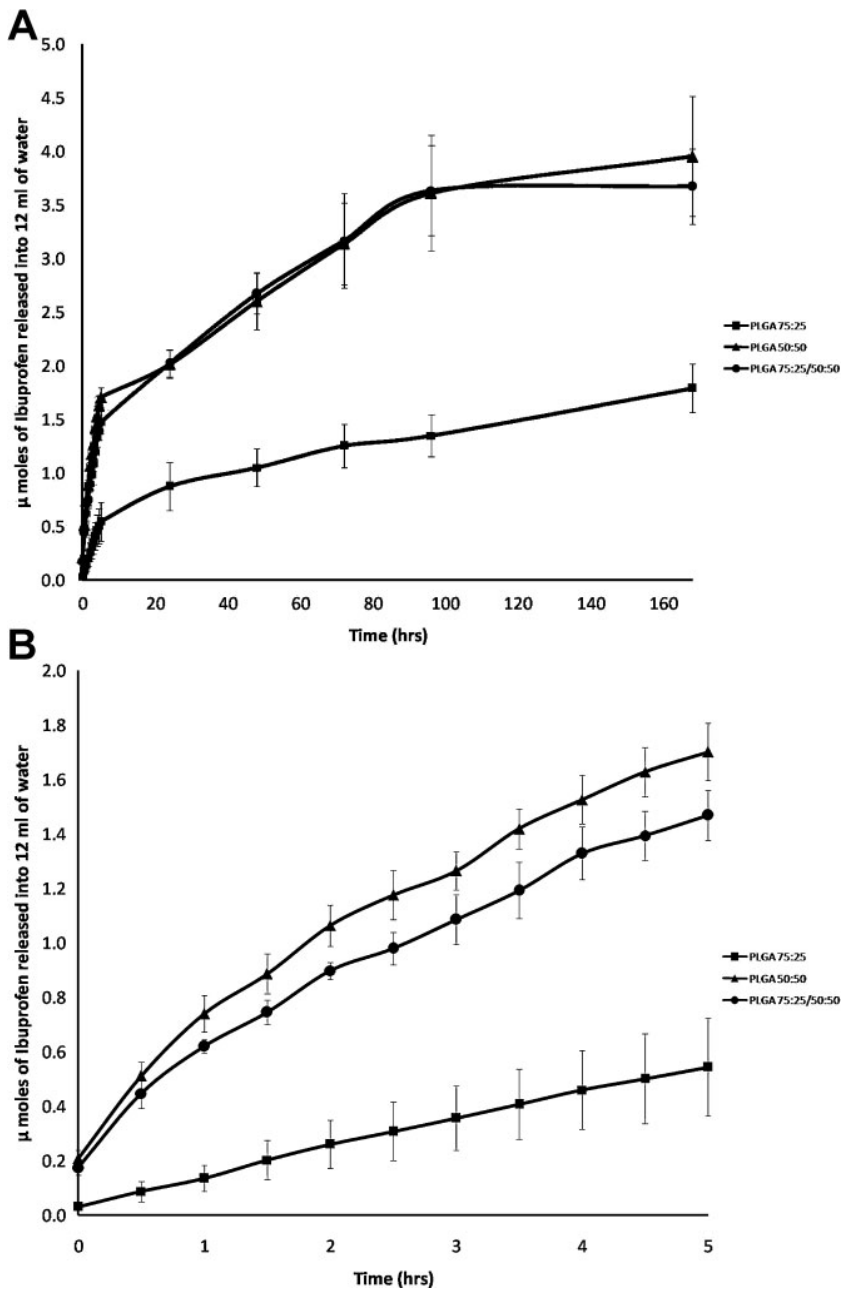

Figure 3. Ibuprofen release profiles for three PLGA scaffolds: $75 / 25$ ( $\mathbf{\square}), 50 / 50$ (A), and a 1:1 blend of these two ( ) dosed with $10 \mathrm{wt} \%$ Ibuprofen. The concentration (in $\mu \mathrm{mol}$ ) of Ibuprofen released into $12 \mathrm{~mL}$ of water was measured by UV/Vis spectroscopy at $222 \mathrm{~nm}$ at various time points for 1 week. Results shown are means $\pm S D$ of three replicate samples looking at release over A) 7 days or B) 5 hours.

\section{Cell Response to Scaffolds}

\section{Cytotoxic and Anti-Inflammatory Responses of Cells to Ibuprofen}

Initially it was necessary to determine which concentrations of Ibuprofen would be anti-inflammatory without being cytotoxic for cells. Accordingly both the Ibuprofen sodium salt and an isomer mixture of Ibuprofen (acid form) were tested for their effects on viability of fibroblasts (results summarized in Table II). Both forms of Ibuprofen performed similarly, with cells tolerating concentrations of Ibuprofen up to $10^{-3} \mathrm{M}(P<0.05)$ but showing a cytotoxic response at concentrations of $10^{-2} \mathrm{M}$. For future studies the concentrations of Ibuprofen investigated did not exceed $10^{-3} \mathrm{M}$.

We next examined the effects of Ibuprofen on LPS and TNF induced NF- $\kappa B$ activation in fibroblasts (Figs. 5 and 6). 


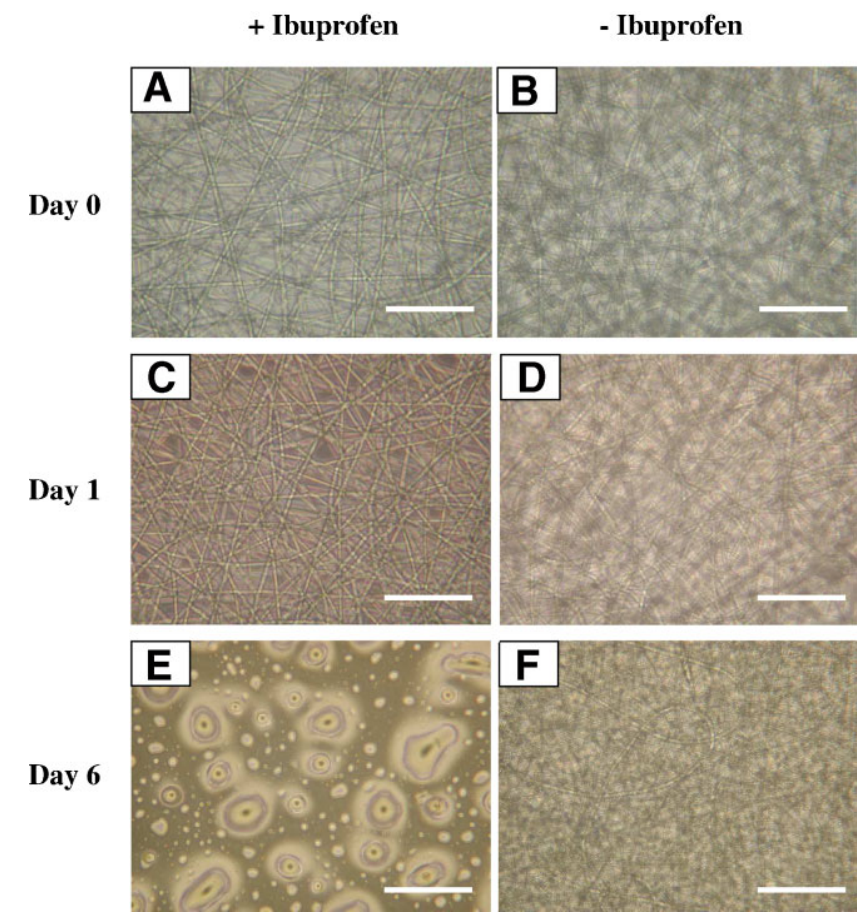

Figure 4. In vitro degradation of PLGA 75:25 scaffold in Ringer's solution over time. Optical micrographs of scaffolds with $10 \mathrm{wt} \%$ Ibuprofen on the right-hand side (A), (C), and (E) at days 0,1 , and 6 of incubation in Ringers solution. Scaffolds without lbuprofen on the left-hand side (B), (D), and (F). Scale bar $=100 \mu \mathrm{m}$.

Concentrations of Ibuprofen of $10^{-4}$ and $10^{-3} \mathrm{M}$-both the Ibuprofen salt and the Ibuprofen isomer mix - were capable of significantly reducing the response to LPS and TNF- $\alpha$ as illustrated in Figure 5 and quantitative data is shown in Figure 6. In these experiments LPS and TNF- $\alpha$ produced $80 \%$ activation of NF- $\kappa$ B. While the inhibitory effects of Ibuprofen were small they were clearly significant against these major pro-inflammatory stimulators.

Table I. Effect of Ibuprofen and $\mathrm{pH}$ on in vitro degradation of PLGA scaffolds.

\begin{tabular}{|c|c|c|c|c|c|c|c|}
\hline \multirow[b]{3}{*}{ Day } & \multirow[b]{3}{*}{ Polymer } & \multicolumn{6}{|c|}{ Extent of visible degradation } \\
\hline & & \multicolumn{3}{|c|}{ Control scaffolds } & \multicolumn{3}{|c|}{ +Ibuprofen scaffolds } \\
\hline & & pH 6 & $\mathrm{pH} 7.4$ & $\mathrm{pH} 8.5$ & pH 6 & $\mathrm{pH} 7.4$ & $\mathrm{pH} 8.5$ \\
\hline \multirow[t]{3}{*}{0} & $50: 50$ & 0 & 0 & 0 & 0 & 0 & 0 \\
\hline & $75: 25$ & 0 & 0 & 0 & 0 & 0 & 0 \\
\hline & 1:1 of above & 0 & 0 & 0 & 0 & 0 & 0 \\
\hline \multirow[t]{3}{*}{1} & $50: 50$ & 0 & 0 & 0 & + & + & + \\
\hline & $75: 25$ & 0 & 0 & 0 & + & + & + \\
\hline & 1:1 of above & 0 & 0 & 0 & + & + & + \\
\hline \multirow[t]{3}{*}{6} & $50: 50$ & 0 & 0 & 0 & ++ & ++ & ++ \\
\hline & $75: 25$ & 0 & 0 & 0 & ++ & ++ & ++ \\
\hline & 1:1 of above & 0 & 0 & 0 & ++ & ++ & ++ \\
\hline
\end{tabular}

Visible degradation scored as none $=0$, some + or extensive ++ .
Table II. Effect of NaIbu and Ibuprofen isomer mixture on HDF viability (MTT-ESTA assay).

\begin{tabular}{|c|c|c|c|c|c|c|}
\hline \multirow[b]{2}{*}{ Treatment } & \multicolumn{3}{|c|}{ Ibuprofen sodium salt } & \multicolumn{3}{|c|}{ Ibuprofen isomer mixture } \\
\hline & $\begin{array}{c}\text { Viability } \\
(\%)\end{array}$ & SEM & $P$-value & $\begin{array}{c}\text { Viability } \\
(\%)\end{array}$ & SEM & $P$-value \\
\hline Control & 100 & 16.43 & & 100 & 16.43 & \\
\hline $10^{-6}$ & 102.17 & 17.71 & & 109.43 & 15.53 & \\
\hline $10^{-5}$ & 100.43 & 18.55 & & 111.80 & 13.19 & \\
\hline $10^{-4}$ & 98.21 & 14.04 & & 108.56 & 15.71 & \\
\hline $10^{-3}$ & 90.33 & 11.70 & & 101.11 & 18.30 & \\
\hline $10^{-2}$ & 38.25 & 5.79 & $P<0.05$ & 7.20 & 2.47 & $P<0.05$ \\
\hline
\end{tabular}

The effect of $24 \mathrm{~h}$ exposure to Ibuprofen on human fibroblast viability was assessed using the MTT-ESTA assay. Results shown are means \pm SEM of triplicate wells. Values differing from controls are indicated as $P<0.05$.

\section{Cytotoxic and Anti-Inflammatory Responses of Cells to Ibuprofen Scaffolds}

The next stage of experimentation was to place PLLA-PGA scaffolds both unloaded and loaded with Ibuprofen above cultures of fibroblasts in 3D scaffolds. The effect of the PLGA scaffolds on cell viability and on the response of cells to proinflammatory stimulation was then investigated. Additionally we examined the loaded scaffolds in two ways. Some were deliberately left unwashed so that any initial burst release of Ibuprofen would be obtained in these experiments. Others were vigorously washed in $70 \% \mathrm{EtOH}$ and then washed three times in PBS to remove any loosely bound Ibuprofen.

There was no significant effect of the washed and unwashed scaffolds on the viability of the fibroblast monolayers placed under these scaffolds irrespective of whether the scaffolds were loaded with $10 \%$ Ibuprofen or not (results not shown).

One of the implications of this work is that any initial burst release of Ibuprofen from the scaffolds does not appear to be high enough to adversely affect adjacent cellular viability to any significant degree. Calculations of the maximum release of Ibuprofen from an $18 \mathrm{~mm}$ disk (approximately $6 \mathrm{mg}$ in weight) of PLLA-PGA into the $1 \mathrm{~mL}$ of media over $24 \mathrm{~h}$ gave a theoretical maximum of $0.4 \mathrm{mM}$ (as derived from Materials and Methods Section) assuming approximately $15 \%$ release of the $10 \%$ Ibuprofen loaded into the scaffolds.

With respect to the anti-inflammatory effects of Ibuprofen, incubation of 2D monolayers of fibroblasts with the scaffolds containing the acid form of Ibuprofen significantly reduced LPS stimulated NF- $\mathrm{BB}$ translocation in all cases $(P<0.05)$ (Fig. 7). The inhibition observed with the three different scaffolds was not significantly different, and comparable to that observed when cells were incubated with Ibuprofen at $10^{-4} \mathrm{M}$ (an isomer mix) as shown in Figure 6 (previous experiments had shown that cells responded similarly to both the sodium salt or the acid form of Ibuprofen). Therefore it appears that $10 \%$ 

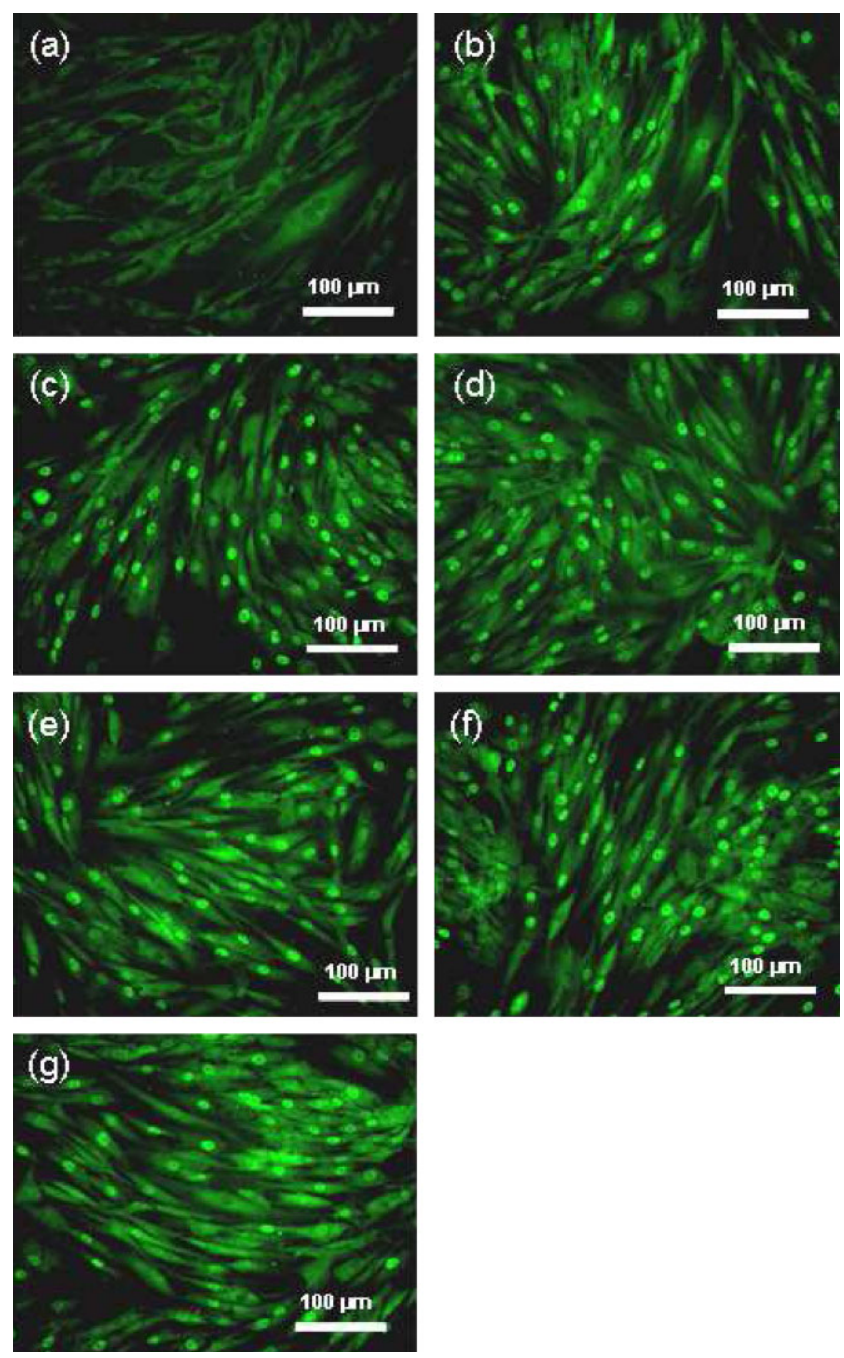

Figure 5. NFKB immunolabeling of $2 \mathrm{D} H \mathrm{HF}$ cultures after treatment with TNF- $\alpha$ LPS, and Ibuprofen. Immunofluorescent labeling of human fibroblasts for the p65 subunit of $\mathrm{NF}-\mathrm{KB}$, demonstrating relative transcription factor activity. a: Control unstimulated cells. b: LPS $(100 \mathrm{ng} / \mathrm{mL})$ stimulated cells. c: TNF- $\alpha(1,000 \mathrm{U} / \mathrm{mL})$ stimulated cells. d: LPS $\left(100 \mathrm{ng} / \mathrm{mL}^{-1}\right)$ plus Ibuprofen $\left(10^{-3} \mathrm{M}\right)$ stimulated cells. e: TNF-a $(1,000 \mathrm{U} / \mathrm{mL})$ and Ibuprofen $\left(10^{-3} \mathrm{M}\right)$ stimulated cells. f: LPS $(100 \mathrm{ng} / \mathrm{mL})$ and Ibuprofen sodium salt $\left(10^{-4} \mathrm{M}\right)$ stimulated cells. g: TNF- $\alpha(1,000 \mathrm{U} / \mathrm{mL})$ and Ibuprofen sodium salt $\left(10^{-4} \mathrm{M}\right)$ stimulated cells

Ibuprofen loaded into scaffolds was released from the scaffolds in concentrations appropriate to inhibit inflammatory signaling in fibroblasts.

We next examined the effect of the scaffolds containing Ibuprofen on cells cultured in 3D. Example images of the appearance of these cells in 3D are shown in Figure 8. While it is technically challenging to estimate NF- $\mathrm{KB}$ activation using the p65 translocation in $3 \mathrm{D}$, two points could be noted from this study. Firstly there was less activation of the cells with LPS in 3D than 2D (as has been reported from this and other laboratories cells often cope better with insults when in 3D rather than 2D (Sun et al., 2006)) and secondly the $10 \%$ Ibuprofen scaffolds were capable of reducing the LPS activation of NF- $\mathrm{KB}$ in these cells in 3D.

\section{Ability of Ibuprofen Loaded Scaffolds to Support Cell Attachment and Proliferation}

Finally a comparison of fibroblast attachment and proliferation on the scaffolds showed that fibroblasts attached and proliferated on scaffolds loaded with 1,2 , and $5 \mathrm{wt} \%$ of Ibuprofen as well as on non-loaded scaffolds (Fig. 9A). However, loading of scaffolds with $10 \%$ Ibuprofen did reduce initial cell attachment but this could be partially (see Fig. 9A) or fully (see Fig. 9B) restored to control levels by washing the scaffolds for $24 \mathrm{~h}$ (consistent with scaffolds releasing some of their Ibuprofen).

This shows that the Ibuprofen loaded fibers remain capable of providing a substrate for these cells to attach and migrate on.

\section{Discussion}

The aim of this study was to develop a biodegradable electrospun scaffold as a wound dressing capable of both providing a temporary guide for cell migration, i.e., to act as a tissue regeneration scaffold, and also to deliver sufficient anti-inflammatory agent to help cells cope with the stresses of an inflammatory wound bed while providing pain relief for the patient.

We report on a simple methodology for the loading of Ibuprofen into scaffolds which then release the Ibuprofen over several days (with most rapid release in the first $5 \mathrm{~h}$ ). The levels of Ibuprofen being released are sufficient to reduce the response of cells to major pro-inflammatory cytokines without compromising the basic ability of the scaffolds to act as substitute dermal scaffolds for the attachment and migration of human dermal fibroblasts. Thus the main objectives of this work were achieved and these will now be discussed in detail before looking at the next steps that must be undertaken to evaluate these dressings for wound healing purposes.

The first challenge was to obtain reproducible spinning conditions for the production of the electrospun material. There are many factors involved in the electrospinning process and their effect on scaffolds fiber diameter and pore size is still being investigated empirically. The key variables are solution viscosity, surface tension, and viscoelasticity of the spinning solution. These are directly related to the concentration and molecular weight of the polymer, as well as the solvent used. The dielectric properties of the solution also play a key role (Kowalczyk et al., 2008; Mitchell and Sanders, 2006; Thompson et al., 2007). In this study we sought to maintain several key parameters of the spinning process, specifically the voltage, collector type and rotation speed, the distance between the needle and the collector, the solution feed rate, and the solution viscosity.

Another source of variation in electrospinning which is perhaps not well documented is that once the polymer is in solution it can change or degrade on storage and the same concentration of polymer does not always yield a solution 

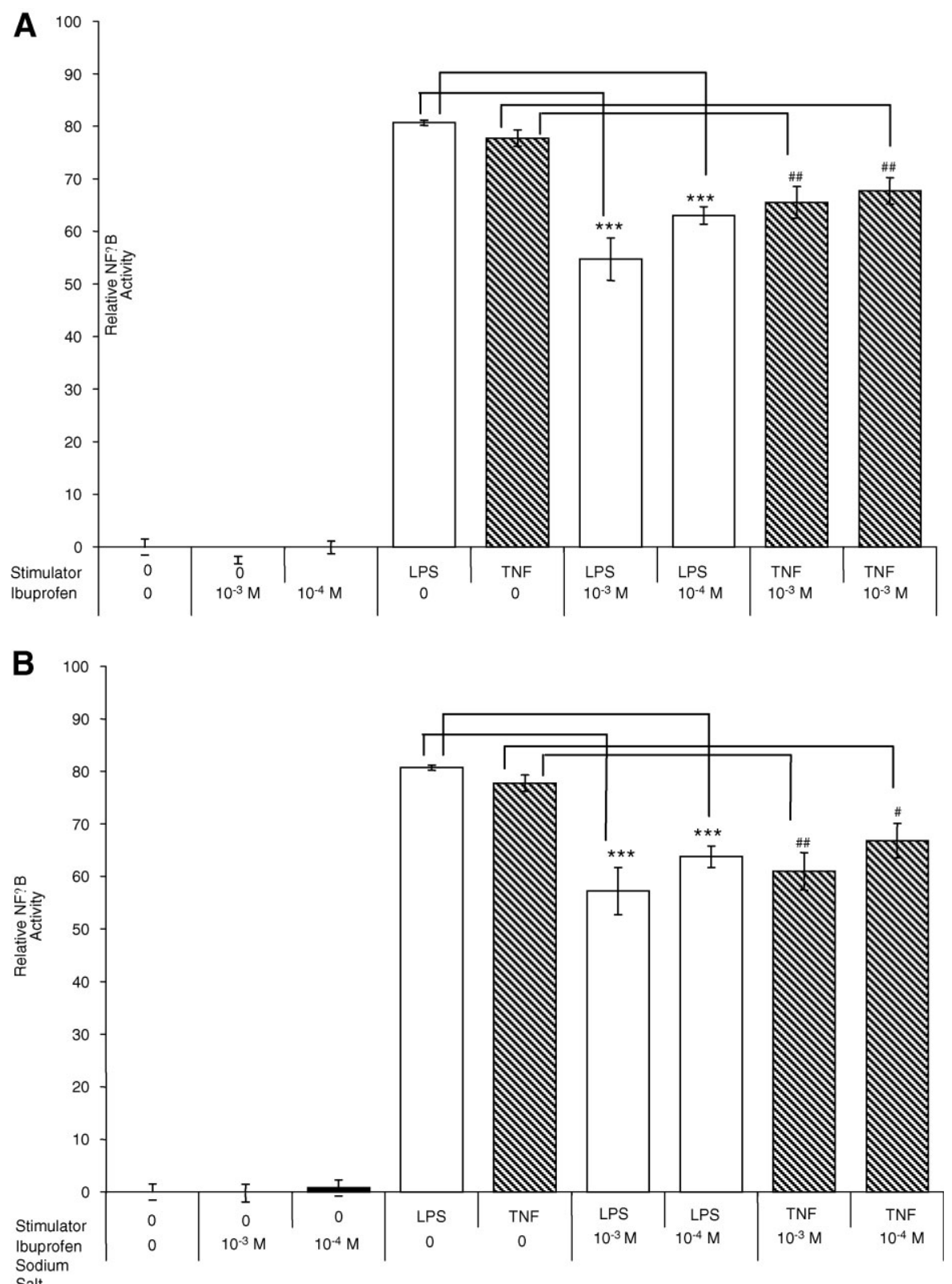

Figure 6. Anti-inflammatory effect of Ibuprofen on HDF cells assessed by NFKB immunolabeling. Effect of (a) Ibuprofen and (b) Ibuprofen sodium salt on NFKB inflammatory signaling. Human fibroblasts were incubated with media or lbuprofen compounds $\left(10^{-4}\right.$ to $\left.10^{-3} \mathrm{M}\right)$ for 15 min before stimulation with LPS (100 ng/mL, open bars) or TNF- $\alpha$ $(1,000 \mathrm{U} / \mathrm{mL}$, diagonal striped bars), or Ibuprofen compounds alone (filled bars) for $90 \mathrm{~min}$. Inflammatory signaling was determined using intracellular localization of NFKB. Key: ${ }^{* * *} P<0.001$ compared to LPS alone, ${ }^{\#} P<0.05,{ }^{\# \#} P<0.001$ compared to TNF- $\alpha$ alone.

with the same viscosity. Thus the molecular weight of the polymer will decrease rapidly over time (particularly the 50/50 PLGA). Therefore, in this study fresh polymer was used for spinning and the molecular weight was checked regularly using gel permeation chromatography. (We did not in this study investigate whether the stored polymers achieved equilibrium on storage and whether the stored polymers would then give predictable scaffolds. This is something worth investigating for the future in order to obtain reproducible conditions for electrospinning.)

However, despite all of these precautions, considerable variability was seen in the initial production of scaffolds. It rapidly became clear that variability occurred when spinning took place in environments of high temperature and variable humidity. The most reproducible scaffolds were those produced in a dry, air-conditioned room (relative humidity $\sim 30 \%$, temperature $21^{\circ} \mathrm{C}$ ). These 


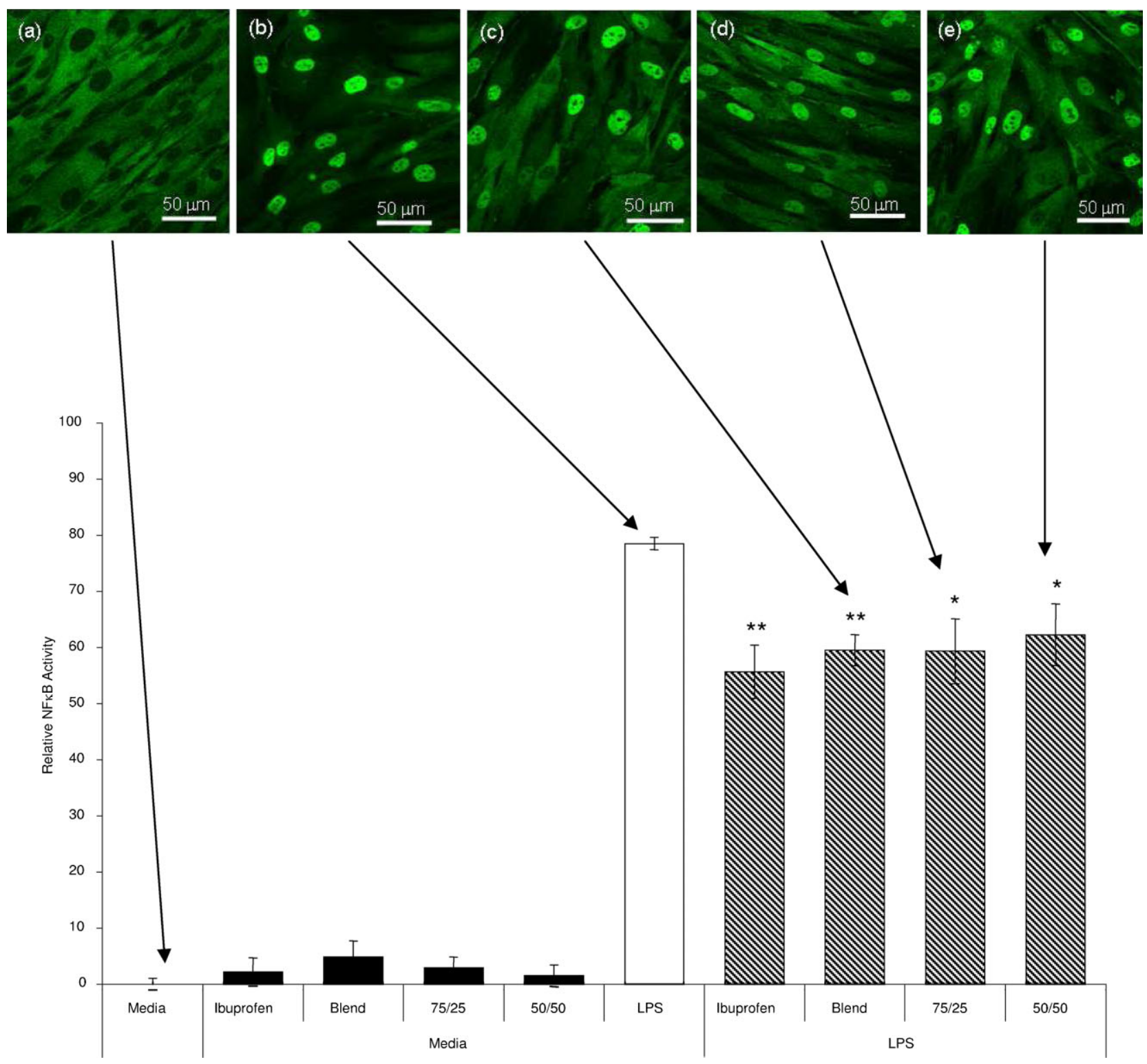

Figure 7. Effect of Ibuprofen loaded scaffolds on TNF- $\alpha$ and LPS stimulated NFKB activation in fibroblasts. Nuclear translocation of the pro-inflammatory transcription factor $\mathrm{NFKB}$ was examined as illustrated in photos (a)-(e). In (a) and quantified in (b) for $2 \mathrm{D}$ cultures of fibroblasts exposed to lbuprofen releasing scaffolds. In (a) control unstimulated fibroblasts are shown. (b) LPS (100 ng/mL) stimulated fibroblasts ( $2 \mathrm{~h}$ exposure). (c) Cells exposed to LPS $(100 \mathrm{ng} / \mathrm{mL}$ ) for $2 \mathrm{~h}$ after pre-incubation with PLA/PGA lbuprofen scaffolds for $24 \mathrm{~h}$. In (c) the scaffold was a 50/50 blend of 75/25 and 50/50 PLA/PGA loaded with Ibuprofen. (d) LPS (100 ng/mL) stimulated fibroblasts exposed to 75/25 PLA/PGA loaded with Ibuprofen. (e) shows LPS $\left(100 \mathrm{ng} / \mathrm{mL}\right.$ ) stimulated fibroblasts exposed to 50/50 PLA/PGA loaded with lbuprofen. Cells were also directly exposed to lbuprofen at $10^{-4} \mathrm{M}$ (an isomer $\mathrm{mix}$ ) as a positive control (referred to as Ibuprofen). Quantification of nuclear translocation of $\mathrm{NF}_{\mathrm{K} B} \mathrm{~B}$ is shown for these fibroblasts in the histograms beneath in (b) for cells under non-stimulated conditions (where the percentage of NFKB in the nucleus did not exceed $5 \%$ ) and for cells stimulated with LPS (100 ng/mL) for $2 \mathrm{~h}$ after pre-incubation with PLA/PGA ibuprofen scaffolds for $24 \mathrm{~h}$. Results shown are means + SEM of triplicate cultures and statistical significance is indicated as ${ }^{*} P<0.05,{ }^{* *} P<0.001$.

scaffolds were then dried under vacuum for a minimum of $24 \mathrm{~h}$ and stored at $4^{\circ} \mathrm{C}$ in sealed bags. Screening all of the scaffolds with SEM showed that these were as expected and identical to batches produced under similar conditions.

We do not claim to have resolved the issue of reproducibility for electrospinning. This remains a major challenge but our experience suggests that temperature and particularly humidity need to be controlled and that the development of electrospinning rigs which take both into account is needed for reproducible scale-up of electrospun scaffold production.

The methodology for loading Ibuprofen into the scaffolds was very simple. The acid form of Ibuprofen could be dissolved in the same solvent as the PLGA polymer (DCM) and this gave homogeneous distribution of Ibuprofen through the scaffold fibers. In contrast the sodium salts did not dissolve in DCM and produced very irregular scaffolds in which the release of drug was much less predictable. Thus 

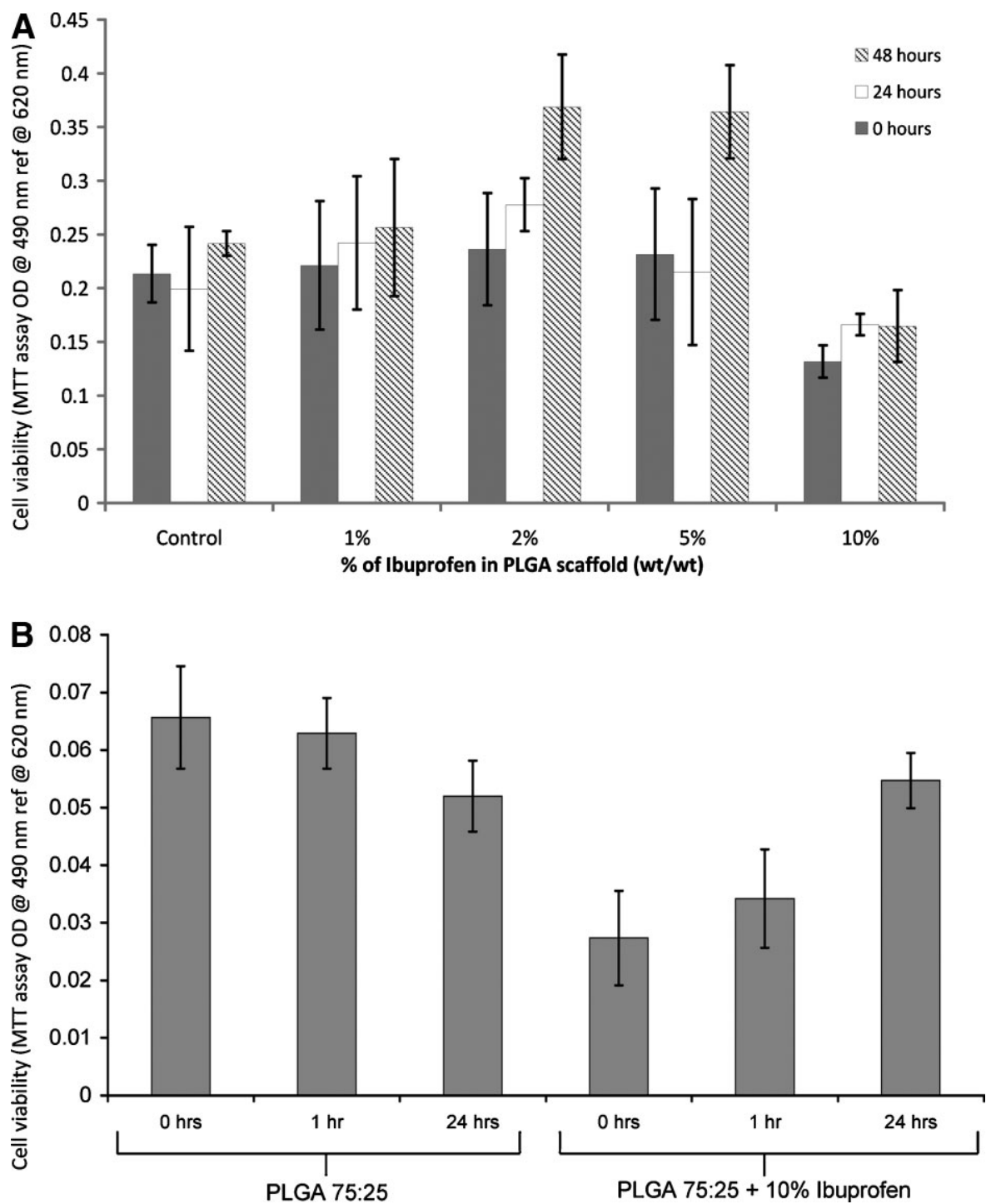

Figure 8. NFKB immunolabeling of $3 D$ HDF cultures after treatment with LPS and lbuprofen scaffolds. Fibroblasts were cultured in a $3 D$ Azowipe scaffold (details as in Materials and Methods Section) and exposed to Ibuprofen loaded scaffolds. Immunofluorescent labeling of cells for the p65 subunit of NF-кB was used to demonstrate the relative transcription factor activity. a: Control unstimulated cells. b: HDF stimulated with LPS (100 ng/mL) for $2 \mathrm{~h}$. c: HDF stimulated with LPS (100 ng/mL) for $2 \mathrm{~h}$ after pre-incubation with a $50 / 50$ blend of $75 / 25$ and $50 / 50$ PLA/PGA Ibuprofen scaffolds for $24 \mathrm{~h}$. d: HDF stimulated with LPS (100 ng/mL) for $2 \mathrm{~h}$ after pre-incubation with $75 / 25$ PLA/PGA Ibuprofen scaffolds. e: HDF stimulated with LPS $(100 \mathrm{ng} / \mathrm{mL})$ for $2 \mathrm{~h}$ after pre-incubation with 50/50 PLA/PGA Ibuprofen scaffolds.

the inference is clear-drugs which can be dissolved in the organic solvent of the polymer can be directly spun into the scaffold fibers. Further work is in progress to check if other drugs can be loaded into scaffolds in a similar manner but this seems to present a simple approach to drug loading into scaffolds obviating the need for more complex approaches.

The next question was whether the scaffolds would release sufficient Ibuprofen to be of value to the patient (with respect to pain perception) and with respect to helping cells in the wound bed cope with inflammation. This study shows that approximately $30 \%$ of the Ibuprofen loaded was released from the PLGA 50:50 and 75:25/50:50 blend scaffold fibers over 7 days, while $15 \%$ of the Ibuprofen was released from 75:25. It is probable that the reduced release of Ibuprofen from $75: 25$ is due to the slower breakdown of scaffold structure compared to the 50:50 and the 75:25/ blend, even if this was not visibly evident. Additionally, the incorporation of Ibuprofen accelerated fiber breakdown as can be seen from Table II. We were able to confirm that the concentration of Ibuprofen being released was sufficient to attenuate the inflammatory response of fibroblasts to a major pro-inflammatory cytokine, TNF- $\alpha$, and to LPS which would normally be derived from bacteria.

The final question was whether the scaffolds, which were releasing Ibuprofen, still retained the ability to act as scaffolds for skin cell attachment, migration, and prolifera- 

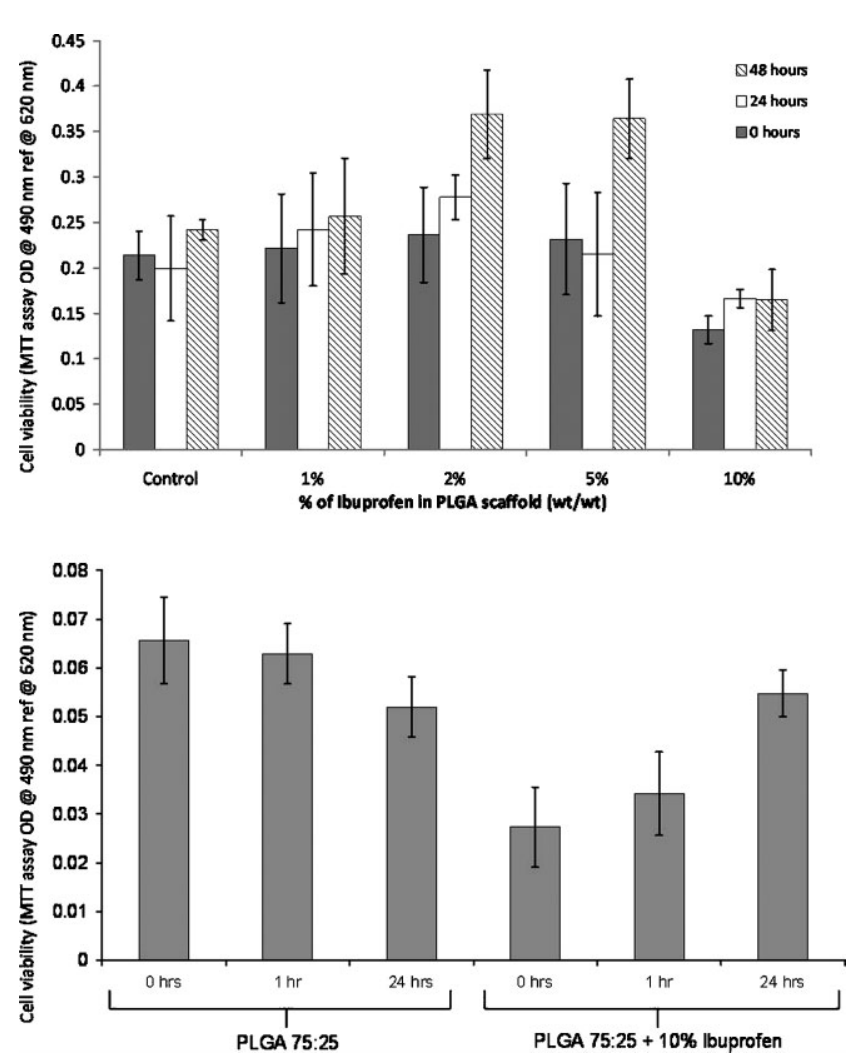

Figure 9. Culture of fibroblasts on Ibuprofen loaded scaffolds. Fibroblasts were cultured on control and Ibuprofen loaded PLGA 75:25 scaffolds (details as in Materials and Methods Section) for $48 \mathrm{~h}$ (a) or 7 days (b) and their survival assessed by MTT-ESTA assay. In (A) scaffolds were loaded with $0 \%, 1 \%, 2 \%, 5 \%$, or $10 \%$ Ibuprofen and then washed by immersion in media for 0,24 , or $48 \mathrm{~h}$ before cells were cultured on them. In (B) scaffolds were either unloaded or loaded with $10 \%$ Ibuprofen and then washed for 0,1 , or $24 \mathrm{~h}$ prior to cell culture. Results shown are means $+\mathrm{SD}$ of triplicate wells of cells.

tion. This was investigated by looking at the attachment and proliferation of human dermal fibroblasts on the scaffolds. Results showed that while cell attachment to the freshly prepared Ibuprofen loaded scaffolds was reduced at the highest concentration of Ibuprofen loaded (10\%) this was restored once scaffolds had soaked in PBS for $24 \mathrm{~h}$ after sterilization, when cell attachment increased back to levels seen in the control unloaded scaffolds. This showed that loading Ibuprofen into the scaffolds did not change their basic ability to act as fibers for skin cell attachment and migration which is encouraging for developing these fibers as tissue guides for wound healing applications.

With respect to wound healing, a certain level of inflammation accelerates wound healing as the release of pro-inflammatory cytokines attracts cells into the wound area-the converse is also true and too high a level of inflammation can retard wound healing (Diegelmann and Evans, 2004; Werner and Grose, 2003). This is certainly thought to be the case in many aggressive chronic wounds where months and even years of matrix metalloprotease activity and secretion of pro-inflammatory cytokines create wound bed environments in which the normal skin cells at the perimeter of the wound fail to survive if they migrate into the wound bed. Thus cells capable of wound healing fail to move into these aggressive wound beds as the extracellular matrix present is under constant degradation due to matrix metalloproteases (e.g., Armstrong and Jude, 2002; Cook et al., 2000).

We hypothesize that the introduction of a synthetic scaffold of fibers capable of supporting normal skin cell attachment and migration and proliferation will help to accelerate wound healing by providing an immediate alternative substrate for unaffected skin cells at the wound margins to migrate across. The simultaneous release of an anti-inflammatory from these fibers will hopefully calm down these aggressive inflamed wound beds.

\section{Conclusions}

We present a conceptually simple approach to a wound healing dressing which provides a temporary substrate for the cells in the wound bed to migrate along while delivering Ibuprofen as an anti-inflammatory agent and pain reliever. This scaffold degrades in 6 days avoiding the need to remove this dressing. The flexibility of the electrospinning technique lends itself to combining the production of fibers to support cell attachment and migration with simultaneous drug release.

The number of chronic non-healing wounds where this could be of benefit are enormous and increasing with an aging population. Such dressings could also be of value in treating superficial burns and scalds where approaches to simultaneously manage pain and accelerate re-epithelialization are also needed.

We thank the White Rose Health Innovation proof of concept fund for support for this study and ESPRC for a Doctoral Training Award for K. Blackwood.

\section{References}

Armstrong DG, Jude EB. 2002. The role of matrix metalloproteinases in wound healing. J Am Pediatr Med Assoc 92(1):12-18.

Blackwood KA, McKean R, Canton I, Freeman CO, Franklin KL, Cole D, Brook I, Farthing P, Rimmer S, Haycock JW, Ryan AJ, MacNeil S. 2008. Development of biodegradable electrospun scaffolds for dermal replacement. Biomaterials 29(21):3091-3104.

Cantón I, Sarwar U, Kemp EH, Ryan AJ, MacNeil S, Haycock JW. 2007. Real-time detection of stress in 3D tissue-engineered constructs using NF-kappaB activation in transiently transfected human dermal fibroblast cells. Tissue Eng 13(5):1013-1024.

Cardenas DD, Jensen MP. 2006. Treatments for chronic pain in persons with spinal cord injury: A survey study. J Spinal Cord Med 29(2):109117.

Christian LM, Graham JE, Padgett DA, Glaser R, Kiecolt-Glaser JK. 2006. Stress and wound healing. Neuroimmunomodulation 13(5-6):337346.

Cook H, Stephens P, Davies KJ, Harding KG, Thomas DW. 2000. Defective extracellular matrix reorganisation by chronic wound fibroblasts is associated with alterations in TIMP-1, TIMP-2 and MMP-2 activity. J Investig Dermatol 115:225-233. 
Diegelmann RF, Evans MC. 2004. Wound healing: An overview of acute, fibrotic and delayed healing. Front Biosci 9:283-289.

Dissemond J, Witthoff M, Brauns TC, Haberer D, Goos M. 2003. pH values in chronic wounds. Evaluation during modern wound therapy. Hautarzt 54(10):959-965.

Gilje O. 1948. On taping (adhesive tape treatment) of leg ulcers. Acta Derm Venereol 28(5):454-467.

Gottrup F, Jørgensen B, Karlsmark T, Sibbald RG, Rimdeika R, Harding K, Price P, Harding KG. 2002. Science, medicine, and the future: Healing chronic wounds. BMJ 324:160-163.

Hinman CD, Maibach H. 1963. Effect of air exposure and occlusion on experimental human skin wounds. Nature 200:377-378.

Jeffcoate WJ, Harding KG. 2003. Diabetic foot ulcers. Lancet 361(9368): $1545-1551$.

Jorgensen B, Friis GJ, Gottrup F. 2006. Pain and quality of life for patients with venous leg ulcers: Proof of concept of the efficacy of Biatain ${ }^{\mathbb{R}}$-Ibu, a new pain reducing wound dressing. Wound Rep Regener 14(3):233239.

Kim K, Yu M, Zong X, Chiu J, Fang D, Seo YS, Hsiao B, Chu B, Hadjiargyrou M. 2003. Control of degradation rate and hydrophilicity in electrospun non-woven poly(D,L-lactide) nanofiber scaffolds for biomedical applications. Biomaterials 24(27):49774985.

Kowalczyk T, Nowicka A, Elbaum D, Kowalewski TA. 2008. Electrospinning of bovine serum albumin. Optimization and the use for production of biosensors. Biomacromolecules 9(7):2087-2090.

Mitchell SB, Sanders JE. 2006. A unique device for controlled electrospinning. J Biomed Mater Res A 78(1):110-120.

Moustafa M, Szabo M, Ghanem GE, Morandini R, Kemp EH, MacNeil S, Haycock JW. 2002. Inhibition of tumor necrosis factor-alpha stimulated NFkappaB/p65 in human keratinocytes by alpha-melanocyte stimulating hormone and adrenocorticotropic hormone peptides. J Invest Dermatol 119(6):1244-1253.
Noonan L, Burge SM. 1998. Venous ulcers: Is pain a problem? Plebology 3:14-19.

Price P, Fogh K, Glynn C, Krasner DL, Osterbrink J, Sibbald RG. 2007. Why combine a foam dressing with Ibuprofen for wound pain and moist wound healing? Int Wound J 4(Suppl 1):1-3.

Price PE, Fagervik-Morton H, Mudge EJ, Beele H, Ruiz JC, Nystrøm TH, Lindholm C, Maume S, Melby-Østergaard B, Peter Y, Romanelli M, Seppänen S, Serene TE, Sibbald G, Verdú Soriano J, White W, Wollina U, Woo KY, Wyndham-White C, Harding K. 2008. Dressing-related pain in patients with chronic wounds: An international patient perspective. Int Wound J 5(2):159-171.

Ralston DR, Layton C, Dalley AJ, Boyce SG, Freedlander E, MacNeil S. 1997. Keratinocytes contract human dermal extracellular matrix and reduce soluble fibronectin production by fibroblasts in a skin composite model. Br J Plast Surg 50(6):408-415.

Sun T, Haycock JW, Szabo M, Hill RP, MacNeil S. 2004. Measurement of NF-kappaB in normal and reconstructed human skin in vitro. J Mater Sci Mater Med 15(7):743-749.

Sun T, Jackson S, Haycock JW, MacNeil S. 2006. Culture of skin cells in 3D rather than $2 \mathrm{D}$ improves their ability to survive exposure to cytotoxic agents. J Biotechnol 122:372-381.

Taepaiboon P, Rungsardthong U, Supaphol P. 2006. Drug-loaded electrospun mats of poly(vinyl alcohol) fibres and their release characteristics of four model drugs. Nanotechnology 17:2317-2329.

Thompson CJ, Chase GG, Yarin AL, Reneker DH. 2007. Effects of parameters on nanofiber diameter determined from electrospinning model. J Polym 48:6913-6922.

Terttu L, Ettler K, Arenbergerova M. 2007. Less pain with Biatain-Ibu: Initial findings from a randomised, controlled, double-blind clinical investigation on painful venous leg ulcers. Int Wound J 4(Suppl 1): 24-34.

Werner S, Grose R. 2003. Regulation of wound healing by growth factors and cytokines. Physiol Rev 83:835-870. 